\title{
REPERTÓRIOS SOBRE LESBIANIDADE NA MÍDIA TELEVISIVA: DESESTABILIZAÇÃO DE MODELOS HEGEMÔNICOS?*
}

\author{
Lenise Santana Borges \\ Pontifícia Universidade Católica de Goiás, Goiânia, Brasil \\ Mary Jane Paris Spink \\ Pontifícia Universidade Católica de São Paulo, São Paulo, Brasil
}

\begin{abstract}
RESUMO: Este artigo objetiva apresentar uma análise discursiva da telenovela Senhora do Destino (Rede Globo, 2004-2005). A postura construcionista, aliada a uma leitura feminista, permitiu compreender a noção de lesbianidade como uma construção social na qual os discursos e a linguagem empregados variam segundo o contexto social e histórico específico. $\mathrm{O}$ foco de análise se deu a partir das práticas discursivas, entendidas como linguagem em ação, sempre múltiplas, situadas e dialógicas. Os resultados desta pesquisa apontam para um duplo efeito na introdução da temática lesbianidade na novela. Se, de um lado, o processo de assimilação da categoria lésbica provoca uma maior "familiarização" na sociedade, bem como a circulação de códigos/modelos propiciam a legitimação de relações afetivo-sexuais entre pessoas do mesmo sexo, de outro, o modo como ocorrem os processos de legitimação/aceitação não propicia uma desestabilização de normas sociais e de modelos hegemônicos.
\end{abstract}

PALAVRAS-CHAVE: Psicologia social; construção social; lesbianidade; telenovela; práticas discursivas.

\section{REPERTOIRES ON LESBIANITY IN TELEVISION MEDIA: DESTABILIZATION OF HEGEMONIC MODELS?}

\begin{abstract}
This article aims to present a discursive analysis of the soap opera Senhora do Destino (Rede Globlo, 2004-2005). The constructionist perspective together with a feminist reading allowed to understand the notion of lesbianity as a social construction in which the discourses and the language adopted vary according to the social and historical context. The analysis was centered on discursive practices, understood as language in action, always multiple, situated and dialogical versions of conversation. The results of this research suggest parallel effects of the introduction of the issue of lesbianity in the soap opera. On one hand, the process of assimilation of the lesbian category provokes a broader "familiarity" in society, as well as the presence of codes/ models that allow the legitimacy of same sex relations. On the other hand, the legitimizing/acceptance processes occur in ways that do not provoke the destabilization of social norms and hegemonic models.
\end{abstract}

KEYWORDS: Social psychology; social constructionism; lesbianity; soap opera; discursive practices.

Apresentamos neste artigo os caminhos teóricos e metodológicos utilizados em uma pesquisa sobre os repertórios a propósito da lesbianidade na mídia televisiva. A escolha da mídia se explica por seu poder de dar visibilidade a fenômenos sociais. Um dos efeitos atribuídos a ela é a reconfiguração das dimensões do espaço público e privado, reduzindo barreiras espaciais e temporais, permitindo construir novas dinâmicas interacionais e configurações de sentidos (Medrado, 2000; Thompson, 2004). Um dos seus mais importantes produtos culturais, a telenovela, pode ser compreendida como um ato de fala, no qual enunciados, vozes, gêneros de discurso e repertórios se articulam para produzir diferentes sentidos sobre o mundo.

Um dos pressupostos desta pesquisa é de que as práticas discursivas que circulam na novela podem ser entendidas como sinalizadores dos discursos sobre lesbianidade que provêm de diferentes matrizes discursivas - da produção acadêmica, dos movimentos homossexual e lésbico, da mídia, do senso comum, entre outros. Nesse sentido, a telenovela é entendida como um gênero de discurso, uma forma particular de linguagem social que atua na veiculação de informações, valores éticos, sociais e entretenimento difundida, neste caso, através de um de seus veículos mais eficientes - a TV. Por meio de narrativas, a novela legitima noções e posições de pessoa, operando na polaridade normal - marginal.

Assistir televisão, especialmente a telenovela, é uma prática social bastante presente no cotidiano da população brasileira. As novelas produzidas no Brasil ocupam lugar privilegiado, e, sendo de fácil acesso, constituem importante fonte de informação e de en- 
tretenimento. As telenovelas participam da produção, manutenção e veiculação de determinados repertórios e, de forma recorrente, entram na pauta de discussão das conversas do cotidiano das pessoas, sobretudo quando se trata de assuntos polêmicos como aqueles referentes às relações de gênero e a sexualidade.

Este artigo analisa a circulação de repertórios sobre lesbianidade na mídia televisiva, explorando as diferentes formas de falar sobre o tema. A telenovela serve aos propósitos de uma análise discursiva psicossocial, que a concebe como uma prática social cuja construção envolve um gênero discursivo muito específico. O processo de produção de uma novela engloba diferentes componentes (autores, diretores, atores, empresa) e estratégias que participam ativamente na produção, circulação e seleção de repertórios, incluindo os/as receptores (leitores/as, telespectadores/as, críticos/as). Além disso, a interação com outras mídias (impressa, digital) realimenta a produção de sentidos sobre determinados temas (Medrado, 2000; Spink \& Medrado, 2000).

Cabe aqui situar o enquadre que mescla "pressupostos epistemológicos construcionistas e teorias feministas sobre gênero"; ambos permitem perceber a cristalização de construções que situam a noção de lesbianidade como desvio. No construcionismo a ênfase recai sobre uma postura desreificante e histórica do conhecimento (Hacking, 2001; Ibañez, 1994). Uma das preocupações da postura construcionista remete-se à produção e aos efeitos do conhecimento científico na vida das pessoas, constatando diferentes pesos e formas de legitimidade na construção do conhecimento, dependendo do lugar e da posição daqueles que produzem definições e noções sobre o mundo. A postura construcionista é uma poderosa aliada para questionar definições concebidas como "naturais" àquilo que se convencionou chamar de homossexualidade/lesbianidade. Essa noção está intimamente comprometida com os saberes e vozes que contribuíram para essa elaboração. As reflexões construcionistas ajudam a perceber que as noções sobre os objetos não são naturais, e sim construídas. Mais do que um referencial teórico, o construcionismo social se constitui, nesta pesquisa, como um olhar crítico sobre a construção do conhecimento produzido sobre a lesbianidade.

$\mathrm{O}$ enfoque de gênero permite pensar em como masculinidades e feminilidades se articulam no interior da trama e ainda como se constroem as relações afetivas no âmbito de uma matriz heterossexual que ordena as práticas afetivas sexuais para uma heterossexualidade compulsória. A noção de matriz heterossexual é desenvolvida por Gayle Rubin (1975), e por Adrienne Rich (1980) e Judith Butler (2003), em seus estudos sobre o sistema sexo-gênero. De acordo com Borges (2008, p. 72), podemos assim compreender o conceito:
A heterossexualidade compulsória é uma ordem instituída socialmente que demanda de todas as pessoas uma definição única e exclusiva na direção da sexualidade. Nela, não existe a possibilidade de se questionar que a orientação sexual [de uma mulher] dirigida a um homem seja inevitável, sendo a heterossexualidade a única forma aceitável de sexualidade. Ela é a regra, a norma, e a homossexualidade, sua antítese. Sendo assim, qualquer variação dessa norma sexual é vista como desvio, como problema, como sinal de imaturidade e de anormalidade. A heterossexualidade, por outro lado, é vista como natural, insuspeita, sinal de um comportamento adulto, maduro e normal.

Sendo assim, a leitura feminista trabalha no sentido de desconstruir o que parece ser uma evidência - a construção da noção de lesbianidade e sua assunção como problema social.

O foco principal de uma análise discursiva na Psicologia Social se dirige para a explicação dos processos pelos quais as pessoas descrevem, explicam ou apresentam o mundo em que vivem, inclusive elas mesmas. As práticas discursivas, de acordo com Spink e Medrado (2000), são "as maneiras a partir das quais as pessoas produzem sentidos e se posicionam em relações sociais cotidianas" (p. 45), e sua análise pode ser feita do ponto de vista da sua dinâmica (enunciados orientados por vozes), da sua forma (gêneros de discurso) e dos conteúdos (repertórios). Potter e Wetherell (1987) definem repertório como o conjunto de termos, descrições, lugares-comuns e figuras de linguagem que estão frequentemente agrupados em torno de metáforas e imagens, utilizando unidades de construção dos discursos e estilos gramaticais próprios. Ainda segundo os autores, esses dispositivos linguísticos são utilizados em distintas produções discursivas, por exemplo, nos discursos veiculados pela ciência e pela mídia, atuando como substrato para a argumentação.

\section{Método}

A opção por analisar Senhora do Destino (2004-2005) justifica-se por ter sido a primeira novela da televisão brasileira a apresentar um relacionamento entre mulheres de forma continuada - elas não desaparecem no meio da trama como em novelas anteriores - e explícita - a relação é nomeada e discutida ao longo da novela. As personagens se enamoram, vivem conflitos ante a possibilidade de se relacionar com uma pessoa do mesmo sexo e a capacidade de se aceitarem e serem aceitas, passam a coabitar, a viver em um modelo conjugal e, finalmente, decidem adotar uma criança. Nas novelas anteriores, a narrativa sobre a lesbianidade era interrompida por algum incidente - como em Vale Tudo (1988-1989) e Torre de Babel (1998-1999) - ou, 
se mantida, permanecia no nível da insinuação - como foi o caso em Mulheres Apaixonadas (2003).

A novela Senhora do Destino, de autoria de Agnaldo Silva, foi veiculada no horário nobre da Rede Globo entre Junho de 2004 e Março de 2005. A novela tinha como protagonista central Maria do Carmo (Suzana Vieira). Sua trama gira em torno dessa personagem que vive uma história da superação do abandono pelo marido, além do sequestro de sua filha na viagem do interior de Pernambuco para o Rio de Janeiro. O irmão de Maria do Carmo, Sebastião, é o elo que conecta os demais personagens. Sebastião tem uma filha, Eleonora (Mylla Crhistie), que fará par com Jenifer (Bárbara Borges), filha de Giovani (José Wilker). A novela foi uma recordista de audiência, e as personagens lésbicas causaram grande impacto, gerando inúmeras reportagens na mídia impressa.

As vidas de Eleonora (Leo) e Jenifer (Jen) só vão se cruzar a partir do capítulo 50, em decorrência dos elos familiares compartilhados: Leo é sobrinha de Maria do Carmo, filha de seu irmão Sebastião, e Jen é filha de Giovanni Improtta, apaixonado por Maria do Carmo, e irmã de João Manoel (Heitor Martinez), namorado de Regininha, irmã de Leo.

O envolvimento de Leo e Jen vai se estreitando em uma série de encontros, desde saídas para pizza e cinema até eventos familiares, marcados por despedidas com "selinhos". A princípio, a relação entre elas é vista como "uma amizade", mas não está isenta de comentários jocosos da "galera de rapazes" e da reação dos parentes frente à ameaça de uma possível relação não convencional. A crescente pressão leva Giovanni a conversar com Jen, na tentativa de esclarecer o que estava de fato acontecendo entre as duas, porque, para ele, os sentimentos de Eleonora não eram os mesmos de sua filha.

Jen se surpreende com a fala do pai e comenta o ocorrido com o irmão, que confirma que elas estavam sendo chamadas de "sapatão". Ela se desespera e vai ao encontro de Leo no hospital onde esta trabalha como médica. Jen se desorienta ainda mais ao ouvir a declaração de amor de Leo, que quer viver uma relação com ela. Ante a revelação de Leo e do que pode significar a proximidade entre as duas, Jen foge. A tristeza se abate sobre as duas, que ficam sem se ver por vários capítulos. Os familiares não deixam de perceber a tristeza das duas, e a família de Jen tenta aproximá-la do deputado Thomas Jefferson (Mario Frias), amigo de Giovanni. Apesar das investidas do deputado e de suas tentativas de iniciar um relacionamento mais íntimo, Jen se recusa a uma maior aproximação. Eles até trocam alguns beijinhos, mas quando ele propõe que eles assumam a relação e menciona o nome de Leo, ela fica irritadíssima, vai para um bar e toma um "porre".
Durante um mês elas ficam sem se encontrar, apesar das tentativas empreendidas por Leo. Embora Jen esteja triste, se recusa a falar com Leo. A mãe de Leo, Janice, ao ver Jen na frente de sua casa resolve intervir e vai conversar com ela. Leo faz uma nova tentativa por telefone e chama Jen para uma conversa "olho no olho". Giovanni também chama a filha para uma conversa e sugere que Jen pare de fugir e encare a situação de frente, dizendo que está ao lado dela para o que der e vier. Jen finalmente vai ao encontro de Leo e as duas seguem para o apartamento de uma amiga de Leo. Jen diz que não entende o que está acontecendo e Leo tenta tranquilizá-la dizendo que as duas vão ter de descobrir juntas. A cena da manhã seguinte no apartamento mostra as duas despertando juntas.

A partir desse episódio, elas se dedicam a pensar como vão encarar as respectivas famílias, após decidirem permanecer juntas. Reações de estranhamento e questionamento acontecem em ambas as famílias. $\mathrm{Na}$ família de Jen, João Manoel é a personagem que fica mais incomodada com a situação e na de Leo, seu pai (Sebastião), ao saber de sua relação com Jen, a expulsa de casa. Porém, depois de conversar com Giovanni, Maria do Carmo e Janice, e de ver a filha trabalhando no hospital, Sebastião reavalia sua decisão e pede para que Leo continue morando com eles. Mesmo com o apoio do pai, Leo resolve que é melhor encontrar um lugar próprio para morar.

Leo comenta com Jen seu desejo de ter filhos. $\mathrm{Na}$ noite de Ano Novo, ela encontra um bebê abandonado na lixeira do hospital em que trabalha, reitera seu desejo a Jen, e elas decidem iniciar o processo de adoção da criança. Ambas as famílias apoiam a luta do "casal", embora o processo de adoção seja iniciado apenas no nome de Leo.

Os meses de fevereiro e março são de preparação do novo apartamento e da expectativa sobre a decisão do juiz sobre a adoção. Em apoio à relação de Leo e Jen, Giovanni cede um de seus imóveis a elas e indica seu advogado para cuidar do processo de adoção. $\mathrm{O}$ juiz finalmente concede a guarda da criança a Leo e o "casal" passa a criá-lo. A novela termina com vários casamentos, entre eles, a união civil das duas, por meio de registro em cartório, que é comunicada às famílias e também com as duas morando juntas no novo apartamento, acompanhadas do filho.

\section{Procedimentos e Análise}

O recorte apresentado neste artigo consistiu em cenas da novela Senhora do Destino (2004-2005). Para a obtenção das cenas da telenovela encaminhamos mensagem eletrônica e por carta à Globouniversidade. O processo de negociação para a permissão do uso das imagens neste estudo se estendeu de março a outubro de 
2005, resultando na obtenção de uma fita de vídeo em formato VHS, contendo o primeiro e o último capítulo da novela; o boletim de programação com a sinopse da história; a descrição das personagens; a transcrição de entrevistas com o autor e o diretor; a relação do elenco de atores/atrizes e de toda a equipe técnica responsável pela execução do projeto, incluindo cenografia, figurino, efeitos especiais e produção de arte; e um resumo dos 220 capítulos da telenovela.

Concomitantemente, foi feita uma pesquisa na Internet buscando cenas da novela por meio da qual encontramos o site de Lee Looper (http://leoandjen. com.br), onde estavam disponibilizadas 151 cenas sobre o casal lésbico e informações sobre a vida das atrizes Mylla Christie e Bárbara Borges, que representaram Eleonora e Jenifer, respectivamente (material disponível para download). Esse acervo possibilitou a reedição das cenas de Leo e Jen, resultando em um único filme. Essa reedição permitiu acompanhar o desenvolvimento da narrativa deste par romântico e, também, editar pequenos recortes da história. Foram produzidos 16 filmes curtos, contendo as narrativas de cada personagem sobre o tema da lesbianidade ou de falas que focalizassem a relação entre Leo e Jen.

A análise focalizou o uso de repertórios sobre lesbianidade, apoiada em estratégias metodológicas desenvolvidas por Spink e Menegon (2000) para a análise de práticas discursivas, amplamente utilizadas pelos participantes do Núcleo de Estudos e Pesquisas em Práticas Discursivas e Produção de Sentidos, do Programa de Estudos Pós-graduados em Psicologia Social, da Pontifícia Universidade Católica de São Paulo NPDPS (por exemplo, Cocchiola, 2004; Medrado, 1997; Passarelli, 1998).

Spink e Menegon (2004) propõem que a análise das práticas discursivas inclua duas possibilidades de apreensão: a primeira refere-se à linguagem em uso e a segunda é mais voltada para os aspectos estruturais da linguagem. Esse tipo de análise requer um duplo movimento que englobe (1) os aspectos performáticos da linguagem - quando, em que condições, com que intenção, de que modo - e (2) as condições de produção - o contexto social e interacional (Bakhtin, 1994) e as construções históricas no sentido foucaultiano (Foucault, 2004).

Devido à presença simultânea de imagens, sons e texto, o material audiovisual requer análises de texto que ultrapassem somente uma análise textual. A interanimação entre os diferentes meios torna o discurso mais dinâmico, fluido e repleto de possibilidades de sentidos, dado que uma cena enunciativa contém distintas modalidades de evento. Outra particularidade da proposta deste estudo foi somar a essas estratégias metodológicas o enfoque de gênero na análise discursiva de um produto midiático.

A edição de cenas para cada personagem possibilitou a análise detalhada dos posicionamentos, da linguagem e da linha de argumento utilizado por cada personagem, articulados com outras informações disponíveis sobre elas, como classe, raça, orientação sexual, idade e grau de instrução. Como o foco da pesquisa era a relação entre Jen e Leo, a análise priorizou cenas entre as duas, delas com as demais personagens e das demais personagens referindo-se às duas.

A edição das cenas permitiu identificar as diversas nomeações utilizadas para se referir à lesbianidade. Assim, as designações identificadas ultrapassam um conjunto de palavras dicionarizadas e com significados estabelecidos e convencionados. Esses repertórios estão inseridos em um contexto específico, com características peculiares e que gera sentidos no cotidiano durante o processo de produção da mensagem e da recepção. Esses sentidos passam a funcionar como novos contextos nos quais outros sentidos podem ser produzidos.

\section{Resultados}

A partir da análise dos repertórios, a novela pode ser dividida em dois momentos. O primeiro engloba os capítulos 50 a 130, nos quais as personagens estão se conhecendo, e inclui o encontro sexual das duas personagens (Quadro 1). O segundo momento, capítulos 131 a 220 , concerne às cenas em que elas passam a viver nos molde um "casal” (Quadro 2).

Quadro 1: Da amizade ao sexo

\begin{tabular}{|l|l|}
\hline CAPÍTULOS & EIXOS TEMÁTICOS PREDOMINANTES \\
\hline $50,51,52,53,55$ & Primeiros encontros \\
\hline $56,70,72$ & "Choque"; primeiro "selinho"; estranhamentos \\
\hline $83,84,85,89,90,92,96,101,103,108,112,113$ & “Amizade"; mais estranhamentos; provocações; primeira nomeação "sapata" \\
\hline 114 & Tensões e nomeação de "lésbica". \\
\hline $116,117,125,127$ & $\begin{array}{l}\text { Desencontros: afirmação e fuga; } \\
\text { Apoios familiares }\end{array}$ \\
\hline 130 & Sexo (insinuação na cama). \\
\hline
\end{tabular}


Até o capítulo 130, "amiga" é a palavra predominante nos repertórios que as personagens adotam para se nomearem, conforme os diálogos relacionados a seguir.

Cena 19 Leo telefona para Jenifer e marca um encontro na Cap.83 sorveteria

Leo Alô, Jenifer! (....)

Jen Eu também tava com saudades de você, dos nossos papos, amiga. Não, não, imagina! não tenho nenhum compromisso, Eleonora. Se eu tivesse eu desmarcava, pronto. Claro, claro, na sorveteria onde a gente se viu naquele shopping, vamos nos encontrar, então, beijos.

Cena 20 Encontro Leo e Jen na sorveteria

Cap. 84

Leo Ah! Desculpa amiga, nem perguntei se você queria variar hoje

Jen Não precisa, pode ser o de sempre

Leo Eu tenho uma péssima mania de resolver tudo por todo mundo

Jen Por mim ta ótimo Eleonora, eu adoro ter alguém que decida por mim.

Leo É por isso que gosto de sair com você, a gente se completa, não é?

Jen É verdade

A aproximação inicial entre Eleonora e Jenifer uma aliança para proteger a relação estabelecida entre o irmão de Jenifer (João Manoel) e a irmã de Eleonora (Regininha) da ira de Sebastião (pai de Eleonora e Regininha) - se desloca do seu motivo original - salvar os irmãos - e se volta para interesses mútuos - estudar juntas, se divertirem. Nesse momento, os encontros enfatizam o prazer da descoberta e do estar em companhia uma da outra, predominando a ideia de amizade, daí a palavra "amiga" estar associada à vinculação inicial entre elas.

Frente ao aprofundamento da relação entre Eleonora e Jenifer, comentários familiares e de pessoas próximas à família denotam julgamentos, avaliações e temores sobre os rumos que a relação possa tomar.

Cena 20 Reação ao selinho de Jen e Leo ao se cumprimenCap 84 tarem.

Gato Caraca meu irmão, vocês viram o que eu vi brother? Qual é a dessas duas? Que é isso?

Shaolin Shh!! ninguém tem nada a ver com isso viu malandro. Uma é sobrinha da Dona do Carmo e a outra é filha do Doutor Giovani, então se essas duas quiserem se agarrar em praça pública ninguém aqui tem nada a ver com isso.
Rapaz da Shao, to contigo cara, cada uma sabe de si meu galera irmão, ninguém se mete

Cena 21 Na rua a galera observa e comenta o "selinho" entre Cap.85 Leo e Jen

Galera Alá, alá, não acredito, alá, não falei. Mulher que pega mulher, isso aí meu Deus do céu. Logo, duas gataças maluco!

Shaolin Meu irmão, o negócio é o seguinte, essas gatas tem bom gosto, sacou? E os mané não tem nada a ver com isso... Vamos embora, que eu tenho muito serviço para fazer hoje.

A relação das duas "amigas", cujos encontros são percebidos em termos de "gostar de ficar juntas", "de sair para conversar, se divertir", não parece mais suficiente aos olhos de João Marcelo, da galera e do pai de Jenifer, Giovani. As perguntas emergem de forma mais direta sobre o status da relação com o pressuposto da existência de um namorado.

Cena 35 Giovani chama Jenifer para uma conversa

Cap. 114

Jen $\quad$ O senhor disse que ia me fazer uma pergunta...

Giovani é, é, sobre você e a Eleonora. Essa sua amizade com a doutora vem a ser exatamente o quê?

Jen Ai, mas que pergunta pai. A amizade que eu tenho com a "doutora" vem a ser aquilo que é, ou seja, uma grande amizade. Eu adoro a Eleonora, eu quero ta o tempo todo com ela, a gente tem sempre assunto para conversar, e se diverte demais quando a gente tá junta, nós somos amigonas.

Giovani Quer dizer... você gosta muito dela como amiga?

Jen E de que outra maneira poderia ser?

Giovani E a doutora, como é que... como é que ela gosta de você?

Jen $\quad \mathrm{O}$ senhor disse que ia me fazer uma pergunta, mas já fez várias viu, e eu não to conseguindo entender o motivo de nenhuma delas, pai. Esse interrogatório todo aí sobre a minha amizade com a Eleonora, por quê?

Giovani Sabe o que é, é que às vezes uma amizade entre duas criaturas pode se tornar muito mais do que isso, entendeu? Talvez por ser uma meninazinha inocente, você ainda não tenha percebido o alcance do apego que há entre vocês duas, entendeu?

Jen Não, não, isso não. Eu... não acredito, pai (chorando), não pode ser.. Eu tava falando da Eleonora, a Eleonora, minha grande querida amiga, praticamente a única que eu tenho. O senhor tá insinuando... 
Giovani Não estou insinuando absolutamente nada, eu não estou insinuando porque não sou um homem de insinuação, imagina. Você me desculpe, mas eu estou afirmando que deve haver um mal-entendido entre vocês duas, mal-entendido esse que você minha filhinha deve tratar de esclarecer.

Jen Levanta e faz menção de sair.

Giovani Escute, escute, venha cá, escute, preste atenção. Eu sou um homem bastante experiente, bastante vivido, calejado até... e olha, qualquer coisa que aconteça aqui dentro da minha casa, a menos que eu seja sei lá, que eu seja assim incendiado deitado na minha própria cama, eu vou tentar entender, ta?

Alertada pelas perguntas feitas por Giovani, Jenifer pergunta ao irmão, João Manoel, como ele percebe a relação dela com Leo. No diálogo transcrito abaixo aparece pela primeira vez a nomeação "sapatona" para o relacionamento das duas.

\section{Cena 35 Jenifer pergunta ao irmão o que ele acha da amiza- Cap.114 de dela com Leo \\ JM E aí, posso saber o motivo da conversa? \\ João Manoel, o que você acha da minha amizade Jen com a Eleonora? Então, andam comentando sobre nós duas? você quiser eu posso repetir o que andam comen- tando aí na rua. \\ Jen Mas falaram o quê? (chorando) \\ Imagine, aquele dia que você tava andando na pra- \\ JM ça com a doutora, né, tava lá e aí dois sujeitos, um olhou para o outro e falou: olha lá, lá vão as duas sapatonas. Aí, não... \\ Não, para com isso! É tudo mentira, ninguém pode Jen dizer uma coisa dessas de mim, eu não fiz nada (gri- tando e jogando as coisas no chão).}

A partir do capítulo 114, quando Jenifer procura Eleonora para ter uma conversa "esclarecedora" sobre o relacionamento de ambas, os termos utilizados vão paulatinamente se deslocando de "amizade" para "paixão”, até chegar na nomeação lésbica.

Cena 38 Eleonora e Jenifer conversam na cafeteria do hosCap. 114 pital

\begin{tabular}{ll}
\hline Leo & Ta tudo bem? \\
Jen & Você é que vai me dizer, sabia que andam falando \\
& mal de nós pelos cantos?
\end{tabular}

Leo As pessoas são muito maldosas.

É verdade, são sim.. mas enquanto eu vinha pro hospital fiquei pensando muito sobre a gente, sobre a nossa amizade, e aí eu cheguei à conclusão que a gente deu bandeira, Eleonora, quer dizer, a gente deu margem para as pessoas falarem, aquela brincadeira de selinho, eu sei que não tem nada a ver, mas as pessoas maldam. Da minha parte não tem nada a ver, da sua parte também não, né???

Leo

Jen

Leo

Jen

Jen

Leo

Jen

Leo

Jen

Leo

Jen

Leo

Jen

Leo

Jen

Leo

Jen

Leo

Jen

Leo

Jen
Da minha parte, também, SIM!

Então você está dizendo que...

Eu me envolvi com você Jenifer

Não, então você..., mas é a primeira vez?

Esse alguém não sou eu, e tira a mão de mim!

Se você quer saber se eu prefiro meninas em vez de meninos, a resposta é definitivamente sim.

Mas você... você já....

Já, já namorei uma garota, a Kátia, uma colega da faculdade, terminou porque ela se mudou para Vitória e desde então eu tenho procurado uma pessoa para viver uma relação séria, limpa, bacana.

Ce tá achando que esse alguém sou eu?

$\mathrm{Eu}$ adoraria que fosse

Esse alguém não sou eu, e tira a mão de mim....

Espera Jen, você não pode ir embora assim, deixar as coisas nesse pé.

Por que não posso?

Porque a gente é amiga.

É mesmo!? Não é isso que estão dizendo por aí.

Você é mais importante do que as pessoas, o que você sente.

Eu não sinto nada, eu nunca fiz nada para alimentar esse seu, essa sua..

Paixão, paixão Jenifer, a palavra é essa.

Você me enganou Eleonora, você ficou posando de amiga, mas tava querendo enrolar, pra ver se eu caía.

Olha aqui garota, o que eu sinto por você é a coisa mais bonita que eu já senti em toda a minha vida, o que eu mais quero nesse mundo é te fazer feliz, e não te enganei, não te enrolei, pelo contrário.. Eu fui tão clara, fui tão limpa, até as pedras da rua já comentam aquilo que só você não é capaz de enxergar, que a gente vai ser feliz juntas

Não, não é isso o que eu quero para minha vida, não vou me tornar uma....

Lésbica!

Você falou, nunca mais olhe para minha cara! 
No capítulo 130, na cena em que estão juntas em um apartamento de uma amiga de Leo, a construção textual e imagética sugere a emergência da sexualidade. A cena das duas acordando seminuas na mesma cama é acompanhada de várias outras que mostram casais heterossexuais em poses de intimidade, sugerindo o intercurso sexual entre elas. Esse capítulo é determinante para a configuração da mudança dos rumos do relacionamento entre elas, um divisor de águas que demarca o deslocamento da amizade para a esfera amorosa/sexual.

Cena 61 Jen e Leo ao chegar no apartamento da amiga de Cap. 130 Leo

Jen Quem é que mora aqui?

Leo Acho que isso não vem ao caso

Jen Você pareceu tão segura quando passou lá na portaria. Quase morri de vergonha...

Leo Jenifer, você tem certeza que quer saber? Esse apartamento é de uma colega do hospital. Ela separou do marido faz um tempo e mora sozinha. De vez em quando ela me empresta a chave e eu venho aqui.

Jen E você vem... com amigas suas?

Leo Nem sempre, mas de vez em quando venho sim. Jenifer, você, você veio aqui porque disse que ia falar na minha frente, olhando no meu olho, que nossa amizade ia acabar pra sempre.

Jen É, é foi isso mesmo...

Leo Então, to esperando, pode começar... (carinhosa). Que que foi, que que foi, Jenifer, porque você está chorando?

Jen Porque, porque eu sei que se a gente deixar de se ver eu vou sentir falta de você, mais do que já to sentindo. E foi por isso que eu fiquei no portão da sua casa, porque eu queria te ver de novo.

Leo Eu também, Jenifer, eu também, fui pra porta da sua casa por causa disso. Eu sinto falta de você, eu morro de saudades!

Jen Eu tenho medo, Leo, eu não sei o que está acontecendo comigo... (chora)

Leo Olha para mim. Eu também, eu também não sei direito o que ta acontecendo, mas uma coisa eu tenho certeza, a gente vai descobrir juntas.
Jen Juntas, Leo?

Leo Juntas, Jenifer, a gente vai descobrir. É o único jeito.

No diálogo acima aparece um certo jogo de palavras de Eleonora, pois em um momento anterior ela assegura a Jenifer de que sabia o que estava ocorrendo - paixão, desejo de ficarem juntas. O recurso ao "nós" - "a gente vai descobrir juntas" - sugere a busca por cumplicidade, equiparando-se a Jenifer na dúvida.

Cena 63 Ao acordarem, após a primeira noite juntas

Cap. 130

Jen E agora Leo, como é que vai ser?Agora que estamos juntas, como vai ser em relação aos outros?

Leo Se dependesse só de mim, não haveria mentira nem subterfúgios na nossa história. Eu contaria tudo para todo mundo.

Jen Até para os seus pais?

Leo E também pro seu pai, pra sua avó e até para o seu irmão, que de vez em quando solta umas piadinhas bem preconceituosas.

Jen Eu nunca teria coragem de fazer isso

Leo Por quê? Você sente vergonha?

Jen Não, não é isso. Mas é que eu tenho medo de magoar a minha família. Sabe, eu não quero causar sofrimentos nas pessoas que eu amo. E eu tenho certeza que eles não vão entender. Não vão entender nem suportar.

Leo Vai ser muito mais difícil se a gente fizer as coisas escondido, Jenifer. Como duas criminosas.

Jen Mas é claro que nós não somos isso.

Leo E não estamos fazendo nada de errado, é uma escolha nossa e estamos felizes, não estamos?

Jen Muito!

A partir do cap. 130, em meados de dezembro, o termo amizade, para nomear a relação entre Eleonora e Jenifer, desaparece, e começam a circular outros, cujos sentidos estão mais ligados à sexualidade, e as outras personagens passam a vê-las como um "casal". A partir do capítulo 131, quando a relação das duas já está consolidada, prevalecem os temas do amor, da família, da maternidade e do casamento, deixando a caracterização da lesbianidade em plano secundário.

Quadro 2: A ideia de "casal"

\begin{tabular}{|l|l|}
\hline CAPÍTULOS & EIXOS TEMÁTICOS PREDOMINANTES \\
\hline $132,133,134,135,139140141142$ & Afirmação da relação e novas tensões \\
\hline 143 & Conversa com o pai de Jen \\
\hline 144,146 & "Abrir o jogo” \\
& Primeira referência à maternidade \\
\hline
\end{tabular}




\begin{tabular}{|l|l|}
\hline 148,149 & $\begin{array}{l}\text { Conversa com o pai de Léo; } \\
\text { Julgamento e sofrimento }\end{array}$ \\
\hline $152,157,160,162,165,168,169,171,172,173$ & Bebê; Maternidade; Adoção \\
\hline $175,176,182,183,185,187,188,190$ & Projeto de morar juntas: procura por apartamento, dificuldades, apoio familiar \\
\hline 191 & Briga, separação das duas \\
\hline $195,199,201,203$ & Reatamento e arrumação do apartamento \\
\hline $207,208,209,210,212$ & Processo de adoção do bebê \\
\hline $213,214,215,218,219,220$ & $\begin{array}{l}\text { Família: duas mães e um bebê } \\
\text { Contrato de união civil } \\
\text { Comemorações }\end{array}$ \\
\hline
\end{tabular}

O diálogo entre Sebastião e Eleonora aponta para diferentes concepções de lesbianidade, bem como modelos explicativos e recomendações práticas. Se para Leo a lesbianidade é vista como uma opção legítima amorosa, que precisa ser vivida, para Sebastião é algo "anormal", que requer tratamento.

Cena 85 Maria do Carmo e Giovani vão até a casa de SebasCap149 tião conversar com ele.

Seb . Vieram pedir para aceitar o vício dessas duas devassas? Pode dar meia volta e ir embora

Maria do Como é que é?

Carmo

Seba Eu não aceito, e me recuso a falar...

Maria do Do que você está falando?

Carmo

Seba Das duas sapatonas, a filha desse cafajeste..Você é um cafajeste e a sua filha é uma sapatona... (...) Eu prefiria que Eleonora tivesse morrido, antes de me dar esse desgosto

Gio Prefiria nada. Ce não sabe do que está falando..

Seba A culpa também é sua, que não soube criar a sua filha, só pode ter sido ela que iludiu Eleonora.

Gio (...) não existe ilusão nenhuma nessa história, Sebastião. As duas sabem perfeitamente o que estão fazendo. Eu também fico completamente troncho só de pensar no assunto, mas a verdade, Sebastião, a verdade é que as duas se amam.

Seb Eu tenho nojo só de pensar nessas coisas.

Gio Mas essas coisas, Sebastião, acabaram de entrar na nossa família, e elas vieram pra ficar, então será bom você tentar controlar esse nojo.

Seb Antes que isso aconteça eu quero morrer seco!

Maria do Meu irmão, pelo amor de Deus, não diga uma coisa Carmo dessas, você ta falando de morte demais pro meu gosto, sabia? E acontece que vocês estão discutindo é sobre vida, isso, a vida de Jenifer e sua filha, minha querida sobrinha, e a vida de todos nós que somos membros das famílias delas.
Seb (...) Se você acha que eu devo aceitar que a minha filhinha, que eu criei, que eu eduquei, a quem eu amei tanto, gosta de mulher, não gosta de homem está apaixonada por sua filha! (....) Farei o possível para separar as duas.

Gio Não adiantaria. Você acha que se houvesse um jeito de fazer a minha filha Jenifer ter outro tipo de preferência, eu já não teria tentado?

Seb Eu não to conseguindo pensar direito, ta me dando uma gastura, uma raiva, uma vontade de destruir tudo, de sair por aí destruindo o mundo inteiro

Gio Sebastião, me ouve, tudo que você vai conseguir é acabar sendo preso. Eu também sofri gravemente as consequências dessa história. Você não tem que ficar mal com o mundo só porque sua filha tem outro tipo de preferência. Ninguém tem culpa de nada, nem ela. Eu sei que é difícil, eu sou testemunha disso, mas você não tem outra saída. Quer dizer, você só tem uma saída.

Seb E qual é a saída?

Gio Você tem que engolir em seco e aceitar

Seb Entender os motivos dessa sem-vergonhice?

Os termos utilizados pelo personagem Sebastião - "desgosto", "doença", "imoral", "depravação", "safadeza", "desvio de conduta", "tara", "sapatona", "lésbica", "aberração", "vício" e "cafajeste" -, associados à manifestação de "nojo" - "preferiria que a filha morresse" -, são evocados a partir de uma matriz discursiva que coloca a lesbianidade da filha entre os discursos que a concebem desde doença até sem-vergonhice, prevalecendo uma interpretação patologizante. Esse não é um achado que surpreende, pois somos herdeiros de um discurso científico sexológico - erigido sob a égide da medicina psiquiátrica e influenciado pelas "teorias anatômicas". Nele, a noção de homossexualidade/lesbianidade adquire um status de desvio e disfunção. Na fronteira entre o normal e o patológico essas teorias criam a figura da "homossexual nata". Uma ideia bastante difundida 
pelos sexólogos do final do século XIX e início do século XX concebe a sexualidade como congênita, percebendo a lésbica como invertida, um membro do terceiro sexo, uma pessoa que nasceu com alma e mente masculina, mas estava aprisionada em um corpo feminino. A partir da criação da categoria lésbica, as práticas sexuais que fogem à reprodução são consideradas "doenças" (Borges, 2008). Mas, se por um lado, a novela incorpora repertórios decorrentes de um discurso patologizante, ela, como um produto cultural pródigo em integrar expectativas diversas, disponibiliza, faz circular também outros repertórios oriundos de outras matrizes discursivas, cuja tônica não é a patologização, mas sim uma noção naturalizada e idealizada da lesbianidade

Uma cena emblemática da aceitação e inclusão do relacionamento de Leo e Jenifer (capítulo 155) é o brinde proposto por Giovani a Flaviana, no intuito de celebrar o amor entre as duas. Devidamente inseridas no contexto dos rituais de celebração que a família realiza, o diálogo abaixo ilustra as formas pelas quais elas são reasseguradas do lugar que ocupam nos vínculos familiares.

Cena 118 Na casa de Giovani, Daniele e ele reforçam os voCap 183 tos de que Leo e Jen se tornem uma "família".

Daniele (...) Antes de eu me casar e ir para o Recife, eu vou fazer o chá de panela de vocês e quem sabe também o chá de bebê

Giovani É isso que eu quero [risos e abraços], uma família assim no sentido tradicional do termo, porque, apesar do João Manoel, é isso o que nós somos..

O apoio familiar é reforçado por Giovani, que cede um de seus imóveis para Leo e Jenifer morarem. $\mathrm{O}$ contexto produzido favorece outro projeto familiar introduzido na trama: a adoção do bebê, Renato.

Cena 133 Na casa de Giovani, ele oferece apoio para ado-

Cap. 202 ção de Renato e para Flaviana para arrumar o novo apartamento.

Giovani (...) Afinal de contas nós somos praticamente, assim, praticamente da mesma família, por que veja o que aconteceu, o João Manoel com a Gegininha (sic), o "seu Leo" com a Jenifer e a senhora comigo, o Sebastião e eu vamos acabar sendo avós e avôs do mesmo neto

Jen (...) Vão ser avós sim, até do Renato! Bom, o advogado ligou para a Leo e tudo indica que a reposta do juizado vai ser positiva e Leo vai ficar com o Renato.
Cena $140 \mathrm{Na}$ casa de Giovani todos o parabenizam pelo Cap. 208

Leo E o Ministério da Saúde informa amar faz bem para todo mundo

Gio Amar é um santo remédio e casar é melhor ainda, aliás, aqui em Vila São Miguel, a safra de casamento vai ser enorme, um verdadeiro "susto".

Amor, casamento e família são termos que emergem sem tensões ou conflitos, como se as práticas que os constituíssem não fossem distintas para as pessoas em termos de classe social, gênero e, principalmente, neste caso, de orientação sexual. A linearidade do texto da novela antecipa o próximo tema para a dupla Leo e Jenifer, inserindo o coroamento dessa união com um filho.

Se Eleonora e Jenifer já cogitavam morar juntas, o projeto de adoção acelera o processo de coabitação, um dos requisitos para adotar uma criança.

Cena 114 Conversa entre Leo e Jenifer sobre a busca de Cap. 175 moradia

Leo Eu não vou decidir nada sem te mostrar... Afinal, essa vai ser a nossa casa, né?

Jen $\quad$ O que foi, bonitinha?

Leo Eu imaginei agora a gente na nossa caminha, o Renato no quarto dele, dormindo feito um anjo, é tudo que eu mais preciso na vida para ser feliz...

Jen Eu vou te fazer muito feliz, Leo! Tanto bem que você faz pras pessoas, você pode ter certeza, quem vai retribuir sou eu.

\section{Discussão}

O objetivo desta pesquisa foi compreender as formas de se falar sobre a lesbianidade na telenovela Senhora do Destino (2004-2005) a partir da análise discursiva das cenas que versavam sobre a relação das personagens Jen e Leo. A escolha de Senhora do Destino se deveu ao fato de ter sido a primeira novela da televisão brasileira a apresentar como personagens centrais duas mulheres que se enamoram e decidem viver juntas. Por meio dos diálogos entre as personagens, as práticas discursivas funcionaram como vias de acesso para chegar aos discursos sobre lesbianidade, tendo por referência os repertórios e as estratégias discursivas que os sustentam. A visibilidade da lesbianidade na mídia, tomando como exemplo a novela Senhora do Destino, e as incursões da pesquisa permitiram apreender os 
termos utilizados nos dois momentos da novela e o contexto de uso. Duas perguntas nortearam a análise: (a) Quais repertórios sobre lesbianidade a novela está produzindo e divulgando? (b) Em que contextos de uso emergem, quem fala, como fala, etc.?

Os resultados desta pesquisa apontam para um duplo efeito da introdução da temática lesbianidade na novela. Por um lado, há um processo de assimilação do termo lésbica, provocando o efeito de maior "familiarização" do público com o assunto, bem como de circulação de códigos/modelos que propiciam a legitimação de relações entre pessoas do mesmo sexo. Por outro, a forma como ocorrem os processos de legitimação/aceitação não possibilita a desestabilização das normas e dos modelos sexuais hegemônicos. A retórica discursiva da novela é construída a partir da ideia de "casal", cuja referência se inscreve na Biologia (macho e fêmea), modelo naturalizado da expressão de sexualidade e que orienta a caracterização da relação entre Elenora e Jenifer em termos de polaridades de gênero. Eleonora é retratada como uma mulher decidida, que sabe o que quer e prefere enfrentar as situações sem subterfúgios, já Jenifer aparece como alguém que tem maior dificuldade de saber o que quer, apresenta dúvidas sobre si mesma e é retratada como a parte mais emocional e frágil da dupla.

Mais do que veicular informações, a mídia também produz saberes, formas específicas de comunicar o que é masculino e feminino. Segundo Foucault (2004, p. 55), discursos são práticas que sistematicamente "formam os objetos de que falam", e não se reduzem a um conjunto de signos que remetem a conteúdo ou representações. As maneiras como são valorados os gêneros implica manutenção ou subversão de comportamentos, sentimentos e interdições que ajudam a moldar a vida de homens e mulheres.

Assim, apesar do inegável avanço na discussão de temas pouco visibilizados na mídia, a inclusão do tema lesbianidade na novela, embora contemple a necessidade de explorar assuntos pouco abordados, é insuficiente para desconstruir/desestabilizar valores tradicionais.

No contexto da novela, os repertórios sobre lesbianidade passam da designação lésbica/homossexual, termos criados no final do século XIX, a outras nomeações mais estigmatizadas e menos politicamente engajadas - "sapatão", "aberração" -, mostrando a circulação de diferentes discursos, cujos sentidos competem entre si. As personagens se dividem entre os/as que utilizam jargões e opinam menos favoravelmente sobre a relação lésbica e aqueles/las que, apesar de não aceitarem a relação, apresentam uma opinião mais favorável.

A polarização entre repúdio e aceitação é um dos motores que os veículos de comunicação utilizam para manter o interesse da audiência. No entanto, essas posições variam durante a linha narrativa da novela, indicando que as opiniões podem mudar segundo os contextos, as interações e negociações ocorridas. Sebastião e Giovani, pais de Eleonora e Jenifer, a princípio manifestaram, de diferentes modos e intensidades, aceitar o relacionamento de ambas. Os diálogos se mostram persuasivos através da força legitimadora da ideia de amor, de casal, de família e de maternidade, culminado na mudança de atitude, primeiro de Giovani e depois de Sebastião. A argumentação que prevalece no texto é baseada na díade amor e família, e as personagens Giovani e Sebastião atuam como guardiões e disseminadores de normas sociais. Assim, a construção de perfis "bem comportados" e adequados, tendo como referência a norma heterossexual e a tônica do amor romântico, aliados ao poder de sedução do drama, constituiu aspecto fundamental para a permanência do assunto na novela. A mídia, especialmente a telenovela, tem uma forma particular de gerar e disseminar mensagens, atuando como espaço institucionalizado e com tendência normalizadora que constrói, reproduz e veicula repertórios sobre comportamento amoroso.

Uma das perguntas suscitada ao longo desta pesquisa é se, ao eleger algumas práticas para serem publicizadas, não silencia arranjos que extrapolam o casamento, o formato familiar, a monogamia, excluindo do campo de legitimação as relações fora do casamento, da monogamia, os solteiros/as, e aquelas que não estão regidas pelo casamento ou pela família.

Ao incluir o tema da lesbianidade, a novela expõe o que Butler (2003) denomina de "o dilema por reconhecimento público". Por um lado, viver sem as normas do reconhecimento público pode gerar sofrimento psíquico e limitações de toda ordem; por outro, se as normas de reconhecimento não forem desafiadas criticamente, a demanda por reconhecimento pode resultar em processos de hierarquia social, reiterando normas sociais.

Apesar de a mídia atuar como uma via para a reflexão, através de seus produtos culturais, a novela aqui analisada não consegue provocar interrogações sobre a lógica do que é concebido como legítimo ou não. Esta parece ser uma tarefa mais compatível com o lugar de pesquisador/a interessado/a - pensar política e criticamente as questões atuais.

É nesse enquadre que a postura construcionista, nas vozes de Ibáñez (1994), Hacking (2001), e Spink e Frezza (2000), possibilita pensar que a criação de categorias específicas, como homossexualidade/lesbianidade e os termos a elas associados (homossexual e lésbica), fazem parte de uma história recente. Permite, portanto, problematizar determinadas definições concebidas como "naturais", incitando a busca de compreensão dos contextos nos quais elas foram produzidas, 
assim como indagar sobre o impacto das categorias na vida das pessoas. Desestabilizar categorias implica questionar, de um lado, os limites das teorizações sobre a homossexualidade/lesbianidade, de outro, abrir caminhos para outras configurações de pensamento.

\section{Nota}

* Financiamento CAPES

\section{Referências bibliográficas}

Bakhtin, M. (1994). The problem of speech genre. In C. Emerson \& M. Holquist ( Eds.), Speech genres and other late essays (pp. 60-102). Austin, Texas: University of Texas Press.

Borges, L. (2008). Repertórios sobre lesbianidade na novela Senhora do Destino: possibilidades de legitimação e de transgressão. Tese de Doutorado, Programa de Pós-graduação em Psicologia Social, Pontifícia Universidade Católica de São Paulo, São Paulo, SP.

Butler, J. (2003). Problemas de gênero: feminismo e subversão da identidade. Rio de Janeiro: Civilização Brasileira.

Cocchiola, R. (2004). A linguagem do stress na televisão: a diversidade de usos no Big Brother Brasil 1. Dissertação de Mestrado, Programa de Pós-graduação em Psicologia Social, Pontifícia Universidade Católica de São Paulo, São Paulo, SP.

Davies, B. \& Harré, R. (1990). Positioning: The discursive production of selves. Journal for the Theory of Social Behaviour, 20(1), 43-63.

Foucault, M. (1984). História da sexualidade l. A vontade de saber. Rio de Janeiro: Graal.

Foucault, M. (2004). A arqueologia do saber. Rio de Janeiro: Forense - Universitária. (Trabalho original publicado em 1969)

Gergen, K. J. (1985). The social constructionist movement in modern psychology. American Psychologist, 40(3), 266-275.

Hacking, I. (2001). La construcción social de qué?. Barcelona: Paidós.

Ibáñez, T. (1994). Psicologia social construcionista. Guadalajara: Universidade de Guadalajara.

Íñiguez, L. (2003). La psicologia social en la encrucijada postconstrucionista: historicidad, subjetividad, performatividad, acción. In Anais do XII Encontro Nacional da Associação Brasileira de Psicologia Social [CD-ROM]. Porto Alegre: Pontifícia Universidade Católica do Rio Grande do Sul.

Kitzinger, C. (1987). The social construction of lesbianism. London: Sage.

Medrado, B. (1997). O masculino na mídia: repertórios sobre masculinidade na propaganda televisiva nacional. Dissertação de Mestrado, Programa de Pós-graduação em Psicologia Social, Pontifícia Universidade Católica de São Paulo, São Paulo, SP.

Medrado, B. (2000). Textos em cena: a mídia como prática discursiva. In M. J. Spink (Org.), Práticas discursivas e produção de sentidos no cotidiano: aproximações teóricas e metodológicas (pp. 243-271). São Paulo: Cortez.

Passarelli, C. A. F. (1998). Amores dublados: linguagens amorosas entre homens no filme La ley del deseo. Dissertação de Mestrado,
Programa de Estudos Pós-Graduados em Psicologia Social, Pontifícia Universidade Católica de São Paulo, São Paulo, SP.

Potter, J. \& Wetherell, M. (1987). Discourse and social psychology: beyond attitudes and behaviour. London: Sage Publication.

Rich, A. (1980). Compulsory Heterosexuality and Lesbian Existence. Signs, 5(4), 631-660.

Rubin, G. (1975). The traffic in women: notes on the "political economy" of sex. In: R. Reiter (Org.), Toward and antropology of woman (pp.157-210). New York: Monthly Review.

Spink, M. J. \& Frezza, R. M. (2000). Práticas discursivas e produção de sentidos: a perspectiva da psicologia social. In M. J. Spink (Org.), Práticas discursivas e produção de sentidos no cotidiano: aproximações teóricas e metodológicas (pp. 17-39). São Paulo: Cortez.

Spink, M. J \& Medrado, B. (2000). Produção de sentidos no cotidiano: uma abordagem teórico-metodológica para análise das práticas discursivas. In M. J. Spink (Org.), Práticas discursivas e produção de sentidos no cotidiano: aproximações teóricas e metodológicas (pp. 41-61). São Paulo: Cortez.

Spink, M. J. \& Menegon, V. M. (2000). A pesquisa como prática discursiva: superando os horrores metodológicos. In M. J. Spink (Org.), Práticas discursivas e produção de sentidos no cotidiano: aproximações teóricas e metodológicas (pp. 63-92). São Paulo: Cortez.

Spink, M. J. \& Menegon, V. M. (2004). Práticas discursivas. In L. Iñiguez (Org.), Manual de análise do discurso em Ciências Sociais (pp. 258-311). Rio de Janeiro: Vozes.

Thompson, J. B. (2004). A mídia e a modernidade: uma teoria social da mídia. Petrópolis, RJ: Vozes.

Lenise Santana Borges é Doutora em Psicologia Social, Professora da Pontifícia Universidade Católica de Goiás, fundadora do grupo Transas do Corpo. Endereço para correspondência: PUC de Goiás - Departamento de

Psicologia. Av. Universitária 1.440, Setor Universitário. CEP: 74605-010. Goiânia/GO. Email: esinel@uol.com.br

Mary Jane Paris Spink é Professora titular da Pontifícia Universidade Católica de São Paulo. Doutora em Psicologia Social pela London School of Economics and Political Science, Universidade de Londres. Endereço para correspondência: PUC de São Paulo - Programa de PósGraduação em Psicologia Social. Rua Monte Alegre, 984, Perdizes. CEP: 05015-000. São Paulo, SP. Email:mjspink@pucsp.br

Repertórios sobre lesbianidade na mídia televisiva: desestabilização de modelos hegemônicos?

Lenise Santana Borges e Mary Jane Paris Spink

Recebido em: 03/02/2009

Revisão em: 18/09/2009

Aceite final em: 16/10/2009 